\title{
Impact of cold adaptation on cardiac tolerance to ischemia/reperfusion. Role of glucocorticoid and thyroid hormones
}

\author{
Sergey Y. Tsibulnikov ${ }^{1}$, Leonid N. Maslov ${ }^{1}$, Natalya V. Naryzhnaya ${ }^{1}$, Vladimir V. Ivanov' ${ }^{2}$, \\ Yury V. Bushov ${ }^{3}$, Nikita S. Voronkov ${ }^{1}$, Amteshwar S. Jaggi ${ }^{4}$, Yi Zhang ${ }^{5}$ and Peter R. Oeltgen ${ }^{6}$ \\ ${ }^{1}$ Laboratory of Experimental Cardiology, Cardiology Research Institute, Tomsk National Research Medical Center, Tomsk, Russia \\ ${ }^{2}$ Laboratory of Experimental Models, Siberian State Medical University, Tomsk, Russia \\ ${ }^{3}$ Department of Physiology, National Research Tomsk State University, Tomsk, Russia \\ ${ }^{4}$ Department of Pharmaceutical Sciences and Drug Research, Punjabi University, Patiala, India \\ ${ }^{5}$ Department of Physiology, Hebei Medical University, Shijiazhuang, Hebei Province, China \\ ${ }^{6}$ Department of Pathology, University of Kentucky College of Medicine, Lexington, KY, USA
}

\begin{abstract}
We have established that the continuous cold exposure (CCE, $4^{\circ} \mathrm{C}, 4$ weeks) causes cold adaptation, increases systolic blood pressure, exerts infarct-limiting effect during coronary artery occlusion (45 $\mathrm{min}$ ) and reperfusion $(2 \mathrm{~h})$. The CCE increases adrenal weight, heart weight and triiodothyronine $\left(\mathrm{T}_{3}\right)$ level but does not change thymus, spleen weight, serum cortisol, corticosterone and thyroxin $\left(\mathrm{T}_{4}\right)$ levels. The long-term $\left(4^{\circ} \mathrm{C}, 8 \mathrm{~h} /\right.$ day, 4 weeks) intermittent cold exposure (LICE) induces adaptation to the cold and increases $\mathrm{T}_{4}$ level. The brief $\left(4^{\circ} \mathrm{C}, 1.5 \mathrm{~h} /\right.$ day, 4 weeks $)$ intermittent cold exposure (BICE) also evokes adaptation to the cold but had no effect on the blood pressure, the cardiac tolerance to ischemia/reperfusion, and does not change thymus, spleen weight, serum cortisol, corticosterone, $\mathrm{T}_{3}$ and $\mathrm{T}_{4}$ levels.
\end{abstract}

Key words: Cold adaptation — Heart - Ischemia - Reperfusion

\section{Introduction}

It is known that prolonged exposure of alien population in the conditions of the Arctic leads to an increase in the incidence of cardiovascular disease (Maslov et al. 2014a). The incidence of hypertension among migrants in the Far North is increased with their length of stay in the Arctic, reaching a level of $61 \%$ in people who have lived in this region for over 15 years (Skavronskaya et al. 2005). The rate of acute myocardial infarction (AMI) among the migrants to the Far North increases dramatically after 7-10 years in the Arctic (Turchinskiy 1979). An unexpected AMI statistic is that $24 \%$ of AMI cases in the polar city of Norilsk Russia occur in individuals under 44 years of age (Turchinskiy and Sakharova 1979).

Experimental studies have shown that prolonged exposure to the cold can have a negative effect on the functional state

Corresponding author: Leonid N. Maslov, Cardiology Research Institute, Tomsk National Research Medical Centre, Russian Academy of Sciences, Kyevskaya 111A, 634012 Tomsk, Russia

E-mail: Maslov@cardio-tomsk.ru of the cardiovascular system in the experimental animals. As early as 1956, it was shown that the 20-day continuous adaptation of rats to cold $\left(+5^{\circ} \mathrm{C}\right)$ led to an increase in their blood pressure (BP) (Adolph 1956). In 1990, Shechtman et al. (1990) found that hypertensive effect of adaptation $\left(+5^{\circ} \mathrm{C}, 39\right.$ days $)$ was maintained, at least for 30 days after placing the rats in the room temperature. However, this data applies only to the long-term continuous exposure to the cold. Meanwhile, the people working in the Far North are subject to the periodic exposure to low temperatures, which evokes in them essential hypertension (Skavronskaya et al. 2005). There is no evidence that the continuous or intermittent exposure to the cold modifies the heart resistance to ischemia and reperfusion. Based on epidemiological data it was possible to hypothesize that the adaptation to the cold will reduce cardiac resistance to the pathogenic impact of ischemia and reperfusion.

However, as early as 1946, Selye established (Selye 1946) that a state of resistance occurred after exposure to extreme stress and also after exposure to excessively strong irritants. Selye called this phenomenon cross-resistance. Later studies 
indicated that after the adaptation to various extreme effects, cross-resistance to coronary artery occlusion and reperfusion could appear (Meerson and Malyshev 1989; Meerson et al. 1989; Maslov et al. 2013, 2014b, 2014c). In 1984, Kuroshima et al. (1984) found that the adaptation by means of shortterm immobilizations increases the body's tolerance to the cold stress. However, it was unknown whether the adaptation to the cold could have cross effects which increase cardiac tolerance to the damaging effect of coronary artery occlusion and reperfusion.

The aim of this study was to evaluate the effect of the cold adaptation on the cardiac tolerance to the pathogenic impact of ischemia-reperfusion, and to assess the role of glucocorticoid and steroid hormones in the infarction-limiting effect of adaptation to cold.

\section{Materials and Methods}

\section{Animals and protocols}

The experimental protocol was approved by the Ethical Committee of the Cardiology Research Institute and it was conformed to the European Union Directive 2010/63/EU. Male Wistar rats weighing 230-260 g were housed at $24 \pm$ $1^{\circ} \mathrm{C}$ with a relative humidity of $60-70 \%$ and a light and dark cycle of $12 \mathrm{~h}$ with free access to water and standard rat chow. We used three research protocols. Rats were exposed to continuous normoxic conditioning for four weeks (28 days) in a cold chamber equipped with a generator Bio-Nova-204G4R1 (NTO Bio-Nova Company, Moscow, Russia). Concentrations of $\mathrm{O}_{2}$ and $\mathrm{CO}_{2}$ in the chamber were continuously measured by TCOD-IR and OLC 20 sensors, and maintained at $20.95 \%$ and $0.03 \%$, respectively, by a MX32 controller (Oldham, France). The first protocol (protocol 1) included animals with continuous cold exposures (CCE), they resided inside the refrigerator chamber $\left(23 \mathrm{~m}^{3}\right)$ at $+4^{\circ} \mathrm{C}$ two rats in a cage for four weeks (Kvetnansky et al. 2012). The second protocol (protocol 2) included rats with long intermittent cold exposures (LICE) which were exposed at $+4^{\circ} \mathrm{C}$ for $8 \mathrm{~h}$ daily for 4 weeks (van Bergen et al. 1992). The third protocol (protocol 3) included animals which were subjected to brief intermittent cold exposures (BICE), which were in a cold chamber at $+4^{\circ} \mathrm{C}$ for 1.5 h daily for 28 days (4 weeks) (Bozhko and Gorodetskaya 1994). The control group consisted of rats which were at a temperature of $24^{\circ} \mathrm{C}$ in vivarium of Laboratory Experimental Cardiology. All rats were included in the experiment $24 \mathrm{~h}$ after termination of the cold exposure.

\section{Cold tolerance test}

Cold tolerance was assessed after $24 \mathrm{~h}$ after finish of cold adaptation. Animals were placed in a cooler at $-18^{\circ} \mathrm{C}$ for
$4 \mathrm{~h}$. The temperature was measured using an electronic thermometer DT-501 (A\&D company Ltd, Japan) at every hour after initiation of exposure to the cold. The number of animals in the experimental groups was 32. There were 8 rats in each group.

\section{Myocardial ischemia/reperfusion}

The rats were anesthetized with $\alpha$-chloralose $(50 \mathrm{mg} / \mathrm{kg}$, i.p.; Sigma-Aldrich, St. Louis, USA). A tracheotomy was performed, and the lungs were ventilated by a rodent ventilator model SAR-830 Series (Central Wisconsin Engineers Inc., Schofield, USA) with room air. Atelectasis was prevented by maintaining a positive end-expiratory pressure of 5-10 $\mathrm{mmH}_{2} \mathrm{O}$. Arterial blood $\mathrm{pH}, \mathrm{PCO}_{2}$, and $\mathrm{PO}_{2}$ were determined throughout the experiment by a gas analyzer model Stat Profile M (Nova Biomedical Corporation, Waltham, MA, USA) and maintained within a normal physiological range by adjusting the respiratory rate and tidal volume. The rectal temperature was maintained between 36.5 and $37.5^{\circ} \mathrm{C}$ during the experiment by using a non-invasive PhysioSuite heating pad (Kent Scientific Corporation, Torrington, USA) during the experiment. The left descending coronary artery was occluded 1-2 mm below the atrial appendage and reperfused as described previously Schultz et al. (1997). The right carotid artery was cannulated for the measurement of blood pressure (BP), which was detected by a pressure transducer model SS13L (Biopac System Inc., Goleta, California, USA) coupled with the device for electrophysiological studies MP35 (Biopac System Inc., Goleta, USA). The same device was used to record the ECG. After 45 minutes of ischemia the ligature was loosen and reestablished blood flow was confirmed by the epicardial hyperemic response. The duration of reperfusion was $2 \mathrm{~h}$. ECG recording was performed during the period of ischemia and $10 \mathrm{~min}$ after the resumption of the coronary circulation with an apparatus for electrophysiological studies MP35. Arrhythmias were quantified during the first $10 \mathrm{~min}$ of ischemia (phase 1a), following $35 \mathrm{~min}$ of ischemia (phase $1 \mathrm{~b}$ ), and the first $10 \mathrm{~min}$ of reperfusion. According to Russell (Russell et al. 1984), arrhythmogenesis of heart rhythm disturbance in the first 10 min of coronary artery occlusion is different from the mechanism of arrhythmia development after $10 \mathrm{~min}$ of ischemia. Therefore, in this study, we analyzed the incidence of arrhythmias during phase $1 \mathrm{a}$ and phase $1 \mathrm{~b}$ and following reperfusion. Recording and processing of the data was performed using the software INSTBSL-W company Biopac System Inc. (Goleta, USA). In assessing cardiac arrhythmias, only the ventricular arrhythmias were taken into account: single premature ventricular beats (sPVC), multiple PVCs, ventricular tachycardia, ventricular fibrillation.

Identification of area of necrosis and area at risk (AAR) was performed by the method of Neckar et al. (2003). AAR 
is the myocardium subject to ischemia-reperfusion. After reperfusion hearts were removed from the chest and washed with a syringe through the aorta cannulated with saline containing $125 \mathrm{IU} / \mathrm{ml}$ heparin and then the ligature was tightened again and myocardium was stained through aorta with $5 \%$ potassium permanganate to determine the AAR. After washing heart sections were made of $1 \mathrm{~mm}$ thick perpendicular to the longitudinal axis with slicer SHARA001-1 (Zivic Instruments, Pittsburgh, USA). The area at risk was not stained with potassium permanganate. Infarct size (IS) was determined by staining with $1 \%$ solution of $2,3,5$-triphenyl tetrazolium chloride for $30 \mathrm{~min}$ at $37^{\circ} \mathrm{C}$. Necrotic myocardium does not stain because the dead cardiomyocytes do not contain dehydrogenases. After completing, coloring slices were placed in $10 \%$ formaldehyde solution for 1 day. The next day, after staining, the right ventricle was removed and slices were scanned on both sides with the scanner HP Scanjet G4050. The AAR and IS was determined by a computerized planimetric method. The infarct size was expressed as a percentage of the area at risk as the IS/AAR. The number of animals in the experimental groups was 48 . In each group there were 12 rats.

\section{Evaluation of cold adaptation}

In a separate series of experiments, the rats were used to determine the level of hormones, adrenal weight, spleen, thymus, heart and brown fat. We did not perform coronary artery occlusion in these rats. One index of cold adaptation of animals is a relative increase in brown fat weight (Lim et al. 2012) therefore interscapular brown fat was weighed in rats. The number of animals in the experimental groups was 51 .

\section{Evaluation of the stress response to cold exposure}

Rats were decapitated $24 \mathrm{~h}$ after completion of exposure to the cold. Blood was centrifuged during $10 \mathrm{~min}$ at $3000 \times g$ and at a temperature $4^{\circ} \mathrm{C}$. The obtained blood serum was frozen and stored at $-18^{\circ} \mathrm{C}$ for not more than 2 weeks. Evaluation of stress damage to the stomach was determined by the number of gastric ulcers and their total area (Scoto and Parenti 1993; Yigiter et al. 2010). The number of animals in the experimental groups was 51 .

\section{Determination of hormones}

The determination of corticosterone content in blood serum was carried out with EIA (Enzyme immunoassay kit) "Corticosterone (Human, Rat, Mouse) ELISA» RE52211 (IBL International GmbH, Hamburg, Germany) using Microplate Reader Infinite 200 PRO (Tecan Austria GmbH, Grodig, Austria). The content of cortisol, triiodothyronine $\left(\mathrm{T}_{3}\right)$ and thyroxin $\left(\mathrm{T}_{4}\right)$ in blood serum was performed with radioimmunoassay kit "Cortisol RIA KIT” IM1841, “T 3 RIA KIT” IM1669 and “T 4 RIA KIT” IM1447 (Beckman Coulter, Immunotech, Prague, Czech Republic). The radioactivity of samples was measured with a multichannel radiometer RIG-12 Progress-RIA (NTC Amplitude Company, Moscow, Russia). The number of animals in the experimental groups was 51.

\section{Statistical analysis}

Results were expressed as means \pm SEM. One-way analysis of variance with Newman-Keuls post hoc test was used to detect differences in parametric variables among adapted and control rats. The Chi squared test was used to detect differences in the incidence of ventricular arrhythmias among groups. Differences were considered significant at $p<0.05$.

\section{Results}

Our studies indicate that continuous exposure to the cold $\left(4^{\circ} \mathrm{C}, 4\right.$ weeks) causes a two-fold increase in brown fat weight in comparison with the intact animals (Table 1). We have also found that LICE $\left(4^{\circ} \mathrm{C}, 8 \mathrm{~h} /\right.$ day, 4 weeks $)$ causes a $50 \%$ increase in weight of the interscapular brown fat in comparison with the intact animals. We found that BICE $\left(4^{\circ} \mathrm{C}, 1.5 \mathrm{~h} /\right.$ day, 4 weeks) does not cause a change in the weight of brown fat. It has been documented that brown fat plays an important role in the thermogenesis and cold acclimatization and that

Table 1. Body, organ and tissue weight of rats after exposure to cold

\begin{tabular}{lcccccccccc}
\hline & $\begin{array}{c}\text { Body weight } \\
(\mathrm{g})\end{array}$ & $\begin{array}{c}\text { Thymus } \\
(\mathrm{mg})\end{array}$ & $\begin{array}{c}\text { Adrenal } \\
\text { glands }(\mathrm{mg})\end{array}$ & $\begin{array}{c}\text { Spleen } \\
(\mathrm{mg})\end{array}$ & $\begin{array}{c}\text { Heart weight } \\
(\mathrm{mg})\end{array}$ & $\begin{array}{c}\text { LV weight } \\
(\mathrm{mg})\end{array}$ & $\begin{array}{c}\text { RV weight } \\
(\mathrm{mg})\end{array}$ & $\begin{array}{c}\text { LV mass } \\
\text { index }(\%)\end{array}$ & $\begin{array}{c}\text { Brown fat } \\
(\mathrm{mg})\end{array}$ \\
\hline Control & 15 & $282.6 \pm 9.3$ & $240.5 \pm 13.2$ & $35.6 \pm 2.1$ & $1059.5 \pm 96.1$ & $956.2 \pm 31.4$ & $808.6 \pm 36.2$ & $148.5 \pm 11.4$ & $0.31 \pm 0.013$ & $300.4 \pm 38.2$ \\
CCE & 12 & $264.8 \pm 3.56$ & $217.0 \pm 12.9$ & $49.7 \pm 2^{*}$ & $933.8 \pm 45.2$ & $1123.3 \pm 46.7^{*}$ & $957.8 \pm 41.7^{*}$ & $166.3 \pm 14.7$ & $0.36 \pm 0.015$ & $764.6 \pm 30.5^{*}$ \\
LICE & 12 & $266.7 \pm 28.9$ & $272.5 \pm 13.7$ & $33.1 \pm 1.1$ & $1052.8 \pm 58.6$ & $984.2 \pm 31.7$ & $846.3 \pm 17.7$ & $138.7 \pm 13.5$ & $0.32 \pm 0.006$ & $566.66 \pm 28.9^{*}$ \\
BICE & 12 & $271.7 \pm 21.1$ & $244.5 \pm 15.2$ & $34.2 \pm 1.9$ & $1060.2 \pm 64.3$ & $1003.4 \pm 58.7$ & $869.6 \pm 21.5$ & $134.5 \pm 15.1$ & $0.32 \pm 0.007$ & $311.7 \pm 21.02$ \\
\hline
\end{tabular}

Data is expressed as mean \pm SEM. ${ }^{*} p<0.01$ versus control; $n$, number of rats in group; CCE, continuous cold exposure $\left(+4^{\circ} \mathrm{C}, 4\right.$ weeks); LICE, long-term intermittent cold exposure $\left(+4^{\circ} \mathrm{C}, 8 \mathrm{~h} /\right.$ day, 4 weeks $)$; BICE, brief intermittent cold exposure $\left(+4^{\circ} \mathrm{C}, 1.5 \mathrm{~h} /\right.$ day, 4 weeks $)$; $\mathrm{LV}$, left ventricle; $\mathrm{RV}$, right ventricle. 


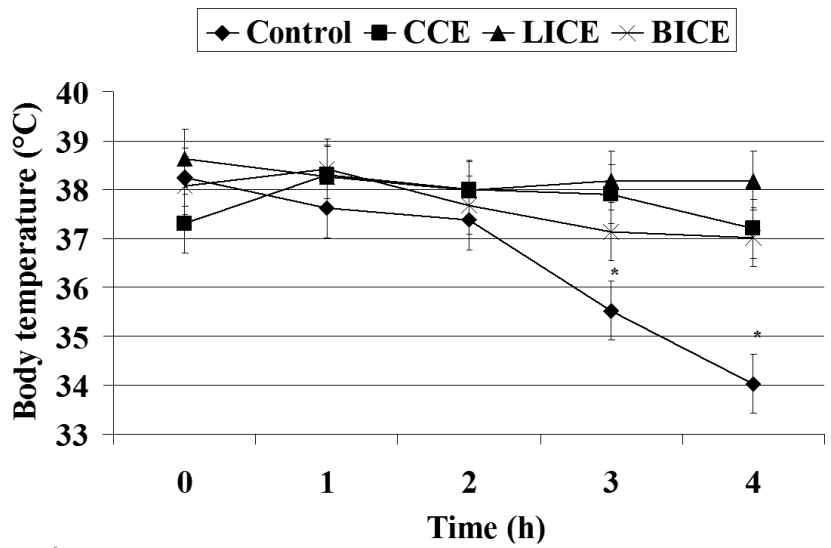

Figure 1. Cold tolerance test $(n=32){ }^{\star} p<0.05$ versus all cold exposure groups. On time 0 , the animal was placed in a cooling chamber. CCE, continuous cold exposure $\left(+4^{\circ} \mathrm{C}, 4\right.$ weeks $)$; LICE, long-term intermittent cold exposure $\left(+4^{\circ} \mathrm{C}, 8 \mathrm{~h} /\right.$ day, 4 weeks $)$; BICE, brief intermittent cold exposure $\left(+4^{\circ} \mathrm{C}, 1.5 \mathrm{~h} /\right.$ day, 4 weeks $)$.

an increase in the weight of brown adipose tissue is an indicator of exposure to cold adaptation (Cannon and Nedergaard 2004). Therefore it is a reasonable hypothesis that resistance to cold would occur after both continuous exposure to the cold and intermittent prolonged exposure to the cold.

Table 2. Hormonal indices of stress response in rats

\begin{tabular}{lccccc}
\hline & $n$ & $\begin{array}{c}\text { Corticosterone } \\
(\mathrm{nmol} / \mathrm{l})\end{array}$ & $\begin{array}{c}\text { Cortisol } \\
(\mathrm{nmol} / \mathrm{l})\end{array}$ & $\begin{array}{c}\mathrm{T}_{3} \\
(\mathrm{nmol} / \mathrm{l})\end{array}$ & $\begin{array}{c}\mathrm{T}_{4} \\
(\mathrm{nmol} / \mathrm{l})\end{array}$ \\
\hline Control & 15 & $2568.5 \pm 93.3$ & $58.3 \pm 12.2$ & $1.04 \pm 0.17$ & $45.6 \pm 4.6$ \\
CCE & 12 & $2587.3 \pm 91.4$ & $47.1 \pm 6.1$ & $1.55 \pm 0.1^{*}$ & $49.9 \pm 2.4$ \\
LICE & 12 & $2571.5 \pm 98.5$ & $49.7 \pm 5.5$ & $0.84 \pm 0.08$ & $71.1 \pm 5.9^{*}$ \\
BICE & 12 & $2589.7 \pm 99.8$ & $41.9 \pm 6.1$ & $0.71 \pm 0.09$ & $64.2 \pm 4.1$ \\
\hline
\end{tabular}

Data is expressed as mean \pm SEM. ${ }^{*} p<0.01$ versus control; $n$, number of rats in group; $\mathrm{T}_{3}$, triiodothyronine; $\mathrm{T}_{4}$, thyroxine. (For other abbreviations, see Table 1).
Indeed, further experiments showed that a $2 \mathrm{~h}$ exposure to cold $\left(-18^{\circ} \mathrm{C}\right)$ causes a decrease in the body temperature in the non-adapted rats to $37.4^{\circ} \mathrm{C}$ after $4 \mathrm{~h}$ temperature drops to $34^{\circ} \mathrm{C}$ (Fig. 1). Cold tolerance occurs in animals subjected to brief $\left(4^{\circ} \mathrm{C}, 8 \mathrm{~h} /\right.$ day, 4 weeks $)$ intermittent exposure to the cold (Fig. 1).

We have found that after the CCE adrenal weight increased by $40 \%$ as compared to the intact animals (Table 1 ). The heart weight after the CCE has increased by $17 \%$. The weight of the left ventricle increased by $18 \%$ while the weight of the right ventricle did not change. The left ventricle mass index was increased by $16 \%$ in CCE group (Table 1). We have found no changes in the weight of thymus and spleen in these rats. We found that after the CCE the $\mathrm{T}_{3}$ level in rat serum increased by $49 \%$ as compared to the intact animals (Table 2). Cortisol, corticosterone and $\mathrm{T}_{4}$ levels in rat serum after CCE were unchanged (Table 2). We have found that intermittent exposure to the cold $\left(4^{\circ} \mathrm{C}, 8 \mathrm{~h} / \mathrm{day}\right.$, 4 weeks) increased $\mathrm{T}_{4}$ level in rat serum increased by $56 \%$ as compared to intact animals (Table 2) but did not affect the weight of the heart, thymus, spleen, adrenal glands ( $\mathrm{Ta}$ ble 1). Cortisol, corticosterone and $\mathrm{T}_{3}$ levels in rat serum after cold adaptation were unchanged (Table 2). We have found that brief intermittent exposure to the cold $\left(+4^{\circ} \mathrm{C}\right.$, $1.5 \mathrm{~h} /$ day, 4 weeks) did not affect the weight of the heart, thymus, spleen, adrenal glands (Table 1). Cortisol, corticosterone, triiodothyronine $\left(\mathrm{T}_{3}\right)$ and thyroxine $\left(\mathrm{T}_{4}\right)$ levels in rat serum after cold adaptation were unchanged (Table 2). We also could not detect gastric ulcers after continuous and intermittent exposures to the cold.

We have demonstrated that the cold adaptation had no effect on the incidence of ischemic and reperfusion of ventricular arrhythmias (Table 3).

We have found an increase in systolic blood pressure from $127 \mathrm{mmHg}$ in the intact rats up to $146 \mathrm{mmHg}$ in rats exposed to continuous cold (Table 4). At the same time, the diastolic blood pressure and heart rate did not change. After the intermittent exposure to the cold we were not able to detect changes in blood pressure and heart rate.

Table 3. The incidence of ventricular arrhythmias

\begin{tabular}{|c|c|c|c|c|c|c|c|c|c|c|c|c|c|}
\hline & \multirow{3}{*}{$n$} & \multicolumn{8}{|c|}{ Ischemia } & \multirow{2}{*}{\multicolumn{4}{|c|}{ Reperfusion (10 min) }} \\
\hline & & \multicolumn{4}{|c|}{ Phase $1 \mathrm{a}(1-10 \mathrm{~min})$} & \multicolumn{4}{|c|}{ Phase $1 \mathrm{~b}(10-20 \mathrm{~min})$} & & & & \\
\hline & & $\begin{array}{c}\text { sPVC } \\
(\%)\end{array}$ & $\begin{array}{c}\text { PVCs } \\
(\%)\end{array}$ & $\begin{array}{l}\text { VT } \\
(\%)\end{array}$ & $\begin{array}{l}\text { VF } \\
(\%)\end{array}$ & $\begin{array}{c}\text { sPVC } \\
(\%)\end{array}$ & $\begin{array}{c}\text { PVCs } \\
(\%)\end{array}$ & $\begin{array}{l}\text { VT } \\
(\%)\end{array}$ & $\begin{array}{l}\text { VF } \\
(\%)\end{array}$ & $\begin{array}{c}\text { sPVC } \\
(\%)\end{array}$ & $\begin{array}{c}\text { PVCs } \\
(\%)\end{array}$ & $\begin{array}{l}\text { VT } \\
(\%)\end{array}$ & $\begin{array}{l}\text { VF } \\
(\%)\end{array}$ \\
\hline Control & 15 & $2(13)$ & $13(87)$ & $10(67)$ & $6(40)$ & $6(40)$ & $9(60)$ & $6(40)$ & $2(13)$ & $13(77)$ & $2(13)$ & $0(0)$ & $0(0)$ \\
\hline CCE & 12 & $2(17)$ & $10(83)$ & $9(75)$ & $5(42)$ & $5(42)$ & $7(58)$ & $5(42)$ & $1(8)$ & $11(92)$ & $1(8)$ & $0(0)$ & $0(0)$ \\
\hline LICE & 12 & $1(8)$ & $11(92)$ & $8(67)$ & $4(33)$ & $4(33)$ & $8(67)$ & $6(50)$ & $1(8)$ & $10(83)$ & $2(17)$ & $0(0)$ & $0(0)$ \\
\hline BICE & 12 & $0(0)$ & $12(100)$ & $8(67)$ & $5(42)$ & $5(42)$ & $7(58)$ & $6(50)$ & $1(8)$ & $9(75)$ & $3(25)$ & $0(0)$ & $0(0)$ \\
\hline
\end{tabular}

Data is expressed as mean \pm SEM. $n$, number of rats in group. sPVC, single premature ventricular complexes; PVCs, premature ventricular complexes; VT, ventricular tachycardia; VF, ventricular fibrillation. (For other abbreviations, see Table 1). 
Table 4. Effect of cold exposure (or adaptation) on systolic blood pressure during ischemia and reperfusion

\begin{tabular}{lccccccc}
\hline & & \multicolumn{5}{c}{ Systolic blood pressure (mmHg) } \\
\cline { 3 - 8 } & $n$ & before ischemia & ichemia & start of reperfusion & $\begin{array}{c}5 \text { minutes of } \\
\text { reperfusion }\end{array}$ & $\begin{array}{c}15 \text { minutes of } \\
\text { reperfusion }\end{array}$ & $\begin{array}{c}45 \text { minutes of } \\
\text { reperfusion }\end{array}$ \\
\hline Control & 15 & $127 \pm 6$ & $127 \pm 8$ & $125 \pm 6$ & $124 \pm 6$ & $119 \pm 7$ & $110 \pm 7$ \\
CCE & 12 & $146 \pm 5^{*}$ & $145 \pm 7^{*}$ & $142 \pm 6^{*}$ & $140 \pm 7^{*}$ & $136 \pm 6^{*}$ & $135 \pm 6^{*}$ \\
LICE & 12 & $126 \pm 5$ & $123 \pm 5$ & $126 \pm 7$ & $125 \pm 7$ & $123 \pm 6$ & $120 \pm 7$ \\
BICE & 12 & $123 \pm 5$ & $125 \pm 7$ & $122 \pm 6$ & $120 \pm 7$ & $115 \pm 6$ & $113 \pm 6$ \\
\hline
\end{tabular}

Data is expressed as mean \pm SEM. ${ }^{\star} p<0.01$ versus control; $n$, number of rats in group. (For abbreviations, see Table 1 ).

As shown in Figure 2, in rats which were subjected to continuous exposure to the cold, the IS/AAR ratio was significantly lower by $33 \%$ than that of the control group. We found no reduction of myocardial infarct size in rats after LICE and BICE.

\section{Discussion}

Our data indicates that after CCE and LICE in rats actually formed adaptation to the cold as evident by the increase in brown fat weight and increased resistance to the effects of low temperature $\left(-18^{\circ} \mathrm{C}\right)$. In animals after BICE we found no change of brown fat weight but increased tolerance to the impact of low temperature $\left(-18^{\circ} \mathrm{C}\right)$. Our studies indicate that there are different degrees of cold adaptation in the three groups. Despite finding no change in brown fat weight in BICE, there could have been changes in the mitochondrial components of the brown fat, leading to the cold tolerance seen in this group (Ricquier et al. 1979; Kuroshima et al. 1984).

We have shown that continuous exposure to the cold causes cardiac hypertrophy, the left ventricle mass index was increased by $16 \%$ in CCE group. The cold induced hypertrophy of the myocardium has been demonstrated by other authors (Hamilton and Ferguson 1972; Harri et al. 1984; van Bergen et al. 1992). Apparently this hypertrophy in the heart is the result of an increase in blood pressure.

Continuous exposure to the cold promoted an increase in adrenal weight but had no effect on the weight of the thymus and spleen. Increased adrenal weight in our view indicates an increase in the adaptive capacity of the organism. After LICE and BICE we found no weight change of these organs. The presented data demonstrates the exposure to the cold used in these studies is not a chronic stress.

We found an increase of the levels in rat blood serum of the hormone $\mathrm{T}_{3}$ after CCE and an increase in $\mathrm{T}_{4}$ after LICE.

The increase in thyroid hormone levels in rat blood serum is consistent with earlier findings of other investigators (McAllister et al. 2000; Vezyraki et al. 2000; Bojko et al. 2008).
We have found an increase in systolic blood pressure after CCE. This data is in agreement with the experimental results of other researchers who have found an increase in blood pressure in conscious rats after acclimatization to the cold ( $+6^{\circ} \mathrm{C}, 4$ weeks) (Fregly et al. 1989). Blood pressure was measured $1 \mathrm{~h}$ after exposure to cold in rats at room temperature $\left(25^{\circ} \mathrm{C}\right)$ (Fregly et al. 1989). Intermittent exposure to cold had no effect on blood pressure.

We have found that only CCE causes a decrease in the IS/ AAR ratio. The mechanism of cardioprotective effect of cold adaptation remains unknown, we hypothesize that it can be associated with an increase in the density of $\beta_{3}$ adrenergic receptor $\left(\beta_{3} \mathrm{AR}\right)$ in the myocardium in response to long-term continuous exposure to cold (Benes et al. 2012). Indeed, there is evidence that the administration of adrenomimetics in animals prior to the coronary occlusion may be the cause of the infarct-limiting effect (Khaliulin et al. 2011; Salie et al. 2012). It has also been shown that pretreatment with $\beta_{3}$ AR agonist BRL37344 can increase cardiac tolerance to ischemia and reperfusion (Aragon et al. 2011; García-Prieto et al. 2014). Thyroid hormones also can be involved in the regulation cardiac resistance to ischemia and reperfusion. It has also been demonstrated that the thyroid receptor agonist DITPA can ameliorate ischemic/reperfusion heart injury

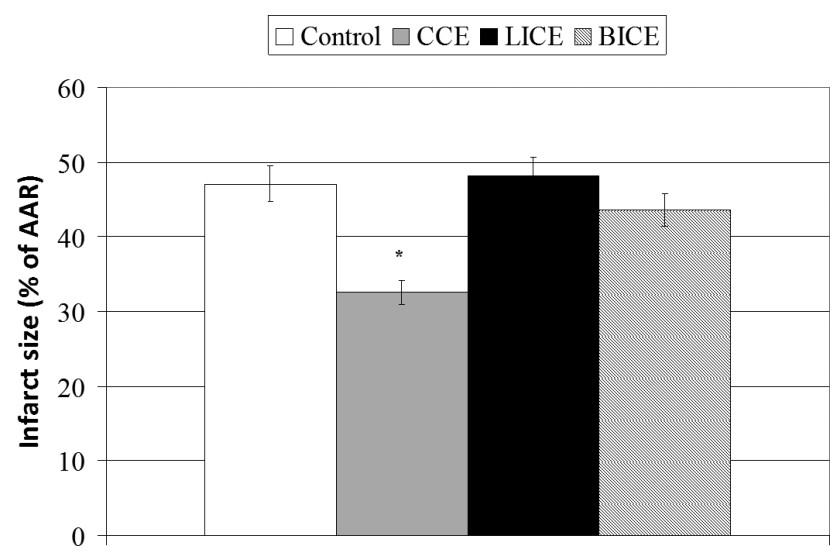

Figure 2. Infarct-limiting effect of cold exposure. ${ }^{*} p<0.01$ versus control. AAR, area at risk. (For other abbreviations, see Fig. 1). 
(Abohashem-Aly et al. 2011). The long-term administration of $\mathrm{T}_{4}$ also enhanced cardiac resistance to ischemia and reperfusion (Kumar et al. 2012).

It has been shown that migrants living long-term in the Far North have a greater frequency of myocardial infarction than in the population of Russians living in the mid-latitudes (Turchinskiy 1979; Turchinskiy and Sakharova 1979). It is now apparent to us that our findings contradict the results of epidemiological studies. In this regard, it should be noted that the increase in the incidence of cardiovascular diseases in the alien population occurs only after living a few years in the Arctic Circle (Turchinskiy 1979). Perhaps after a few years of living in the conditions of the cold and the polar night, a person develops disadaptation. We hypothesize that after a few months in the refrigerator chamber, the phenomena of disadaptation will develop in rats and a high tolerance to cardiac ischemia and reperfusion will be replaced by low tolerance.

Thus, we have established that the continuous exposure to the cold $\left(4^{\circ} \mathrm{C}, 4\right.$ weeks) causes cold adaptation, increases systolic blood pressure, exerts infarct-limiting effect, but does not induce a chronic stress. The intermittent exposure to the cold had no effect on cardiac tolerance to ischemia/reperfusion and is not a chronic stress. The continuous exposure to the cold promotes an increase of $\mathrm{T}_{3}$ level in serum but intermittent exposure to the cold ( $8 \mathrm{~h} /$ day, 4 weeks) contributes to an elevation of serum $\mathrm{T}_{4}$ levels. The continuous and intermittent exposure to the cold had no effect on the glucocorticoid levels. We believe that the study of the molecular mechanisms of the cardioprotective effect of adaptation to cold will not only expand the horizons of our knowledge of heart tolerance to the action of ischemia/reperfusion, but also in the future will contribute to the development of new approaches to the prevention of human ischemic and reperfusion injuries.

Acknowledgment. This research was carried out within the framework of the state assignment AAAA-A15-115120910024-0. This study was supported by Russian Science Foundation grant 16-15-10001.

Conflict of interest. There is no conflict of interest.

\section{References}

Abohashem-Aly AA, Meng X, Li J, Sadaria MR, Ao L, Wennergren J, Fullerton DA, Raeburn CD (2011): DITPA, a thyroid hormone analog, reduces infarct size and attenuates the inflammatory response following myocardial ischemia. J. Surg. Res. 171, 379-385 https://doi.org/10.1016/j.jss.2011.04.009

Adolph EF (1956): General and specific characteristics of physiological adaptations. Am. J. Physiol. 184, 18-28 https://doi.org/10.1152/ajplegacy.1955.184.1.18
Aragon JP, Condit ME, Bhushan S, Predmore BL, Patel SS, Grinsfelder DB, Gundewar S, Jha S, Calvert JW, Barouch LA, et al. (2011): Beta3-adrenoreceptor stimulation ameliorates myocardial ischemia-reperfusion injury via endothelial nitric oxide synthase and neuronal nitric oxide synthase activation. J. Am. Coll. Cardiol. 58, 2683-2691

https://doi.org/10.1016/j.jacc.2011.09.033

Benes J, Novakova M, Rotkova J, Farar V, Kvetnansky R, Riljak V, Myslivecek J (2012): Beta3 adrenoceptors substitute the role of M2 muscarinic receptor in coping with cold stress in the heart: evidence from M2KO mice. Cell. Mol. Neurobiol. 32, 859-869 https://doi.org/10.1007/s10571-011-9781-3

Bojko ER, Evdokimov VG, Potolitsyna NN, Kaneva AM, Varlamova NG, Kochan TI, Vakhnina NA, Shadrina VD, Solonin IuG, Loginova TP, et al. (2008): The pituitary-thyroid axis and oxygen consumption parameters under the conditions of chronic cold exposure in the North. Human Physiol. 34, 215-220 https://doi.org/10.1134/S0362119708020126

Bozhko AP, Gorodetskaya IV (1994): Meaning of thyroid hormones in the implementation of the protective effects of cold adaptation. Pat. Fiziol. Eksper. Terap. 4, 29-32 (in Russian)

Cannon B, Nedergaard J (2004): Brown adipose tissue: function and physiological significance. Physiol. Rev. 84, 277-359 https://doi.org/10.1152/physrev.00015.2003

Fregly MJ, Kikta DC, Threatte RM, Torres JL, Barney CC (1989): Development of hypertension in rats during chronic exposure to cold. J. Appl. Physiol. 66, 741-749 https://doi.org/10.1152/jappl.1989.66.2.741

García-Prieto J, García-Ruiz JM, Sanz-Rosa D, Pun A, GarcíaAlvarez A, Davidson SM, Fernández-Friera L, Nuno-Ayala M, Fernández-Jiménez R, Bernal JA, et al. (2014): $\beta 3$ Adrenergic receptor selective stimulation during ischemia/reperfusion improves cardiac function in translational models through inhibition of mPTP opening in cardiomyocytes. Basic Res. Cardiol. 109, 422 https://doi.org/10.1007/s00395-014-0422-0

Hamilton MJ, Ferguson JH (1972): Effects of exercise and cold acclimation on the ventricular and skeletal muscles of white mice (Mus musculus). I. Succinic dehydrogenase activity. Comp. Biochem. Physiol. A Comp. Physiol. 43, 815-824

Harri M, Dannenberg T, Oksanen-Rossi R, Hohtola E, Sundin $U$ (1984): Related and unrelated changes in response to exercise and cold in rats: a reevaluation. J. Appl. Physiol. 57, 1489-1497 https://doi.org/10.1152/jappl.1984.57.5.1489

Khaliulin I, Halestrap AP, Suleiman MS (2011): Temperature preconditioning is optimal at $26^{\circ} \mathrm{C}$ and confers additional protection to hypothermic cardioplegic ischemic arrest. Exp. Biol. Med. 236, 736-745 https://doi.org/10.1258/ebm.2011.010357

Kumar A, Taliyan R, Sharma PL (2012): Evaluation of thyroid hormone induced pharmacological preconditioning on cardiomyocyte protection against ischemic-reperfusion injury. Indian J. Pharmacol. 44, 68-72 https://doi.org/10.4103/0253-7613.91870

Kuroshima A, Habara Y, Uehara A, Murazumi K, Yahata T, Ohno T (1984): Cross adaption between stress and cold in rats. Pflugers Arch. 402, 402-408 https://doi.org/10.1007/BF00583941 
Kvetnansky R, Ukropec J, Laukova M, Manz B, Pacak K Vargovic $P$ (2012): Stress stimulates production of catecholamines in rat adipocytes. Cell. Mol. Neurobiol. 32, 801-813 https://doi.org/10.1007/s10571-012-9822-6

Lim S, Honek J, Xue Y, Seki T, Cao Z, Andersson P, Yang X, Hosaka $\mathrm{K}, \mathrm{Cao}$ Y (2012): Cold-induced activation of brown adipose tissue and adipose angiogenesis in mice. Nat. Protoc. 7, 606-615 https://doi.org/10.1038/nprot.2012.013

Maslov LN, Vychuzhanova EA, Gorbunov AS, Tsibul'nikov SYu (2014a): The role of dyslipidemia in the pathogenesis of vascular events among Arctic populations. Vestnik RAMN. 7-8, 133-136 (in Russian)

Maslov LN, Naryzhnaya NV, Tsibulnikov SYu, Kolar F, Zhang Y, Wang H, Gusakova AM, Lishmanov YuB (2013): Role of endogenous opioid peptides in the infarct size-limiting effect of adaptation to chronic continuous hypoxia. Life Sci. 93, 373-379 https://doi.org/10.1016/j.lfs.2013.07.018

Maslov LN, Vychuzhanova YeA, Gorbunov AS, Tsibulnikov SYu, Khaliulin IG, Chauski YE (2014c): The role of the thyroid system in adaptation to cold. Ross. Fiziol. Zh. Im. I. M. Sechenova 100, 670-683 (in Russian)

McAllister TA, Thompson JR, Samuels SE (2000): Skeletal and cardiac muscle protein turnover during cold acclimation in young rats. Am. J. Physiol. Regul. Integr. Comp. Physiol. 278, R705-R711

https://doi.org/10.1152/ajpregu.2000.278.3.R705

Meerson FZ, Malyshev IYu (1989): Adaptation to stress increases the heart resistance to ischemic and reperfusion arrhythmias. J. Mol. Cell. Cardiol. 21, 299-303 https://doi.org/10.1016/0022-2828(89)90745-1

Meerson FZ, Ustinova EE, Manukhina EB (1989): Prevention of cardiac arrhythmias by adaptation to hypoxia: regulatory mechanisms and cardiotropic effect. Biomed. Biochim. Acta 48, 583-588

Neckar J, Szarszoi O, Herget J, Ostádal B, Kolár F (2003): Cardioprotective effect of chronic hypoxia is blunted by concomitant hypercapnia. Physiol. Res. 52, 171-175

Ricquier D, Mory G, Hemon P (1979): Changes induced by cold adaptation in the brown adipose tissue from several species of rodents, with special reference to the mitochondrial components. Can. J. Biochem. 57, 1262-1266 https://doi.org/10.1139/o79-167

Russell DC, Lawrie JS, Riemersma RA, Oliver MF (1984): Mechanisms of phase $1 \mathrm{a}$ and $1 \mathrm{~b}$ early ventricular arrhythmias during acute myocardial ischemia in the dog. Am. J. Cardiol. 53, 307-312 https://doi.org/10.1016/0002-9149(84)90444-2

Salie R, Moolman JA, Lochner A (2012): The mechanism of beta-adrenergic preconditioning: roles for adenosine and
ROS during triggering and mediation. Basic. Res. Cardiol. 107,281 https://doi.org/10.1007/s00395-012-0281-5

Schultz JE, Hsu AK, Gross GJ (1997): Ischemic preconditioning is mediated by a peripheral opioid receptor mechanism in the intact rat heart. J. Mol. Cell. Cardiol. 29, 1355-1362 https://doi.org/10.1006/jmcc.1996.0369

Scoto GM, Parenti C (1993): Prevention of stress-induced gastric ulcers by mu- and delta-opioid agonists in the rat. J. Physiol. Paris 87, 385-388

Selye $\mathrm{H}$ (1946): The general adaptation syndrome and the diseases of adaptation. J. Clin. Endocrinol. Metab. 6, 117-230 https://doi.org/10.1210/jcem-6-2-117

Shechtman O, Papanek PE, Fregly MJ (1990): Reversibility of coldinduced hypertension after removal of rats from cold. Can. J. Physiol. Pharmacol. 68, 830-835 https://doi.org/10.1139/y90-126

Skavronskaya TV, Leus AI, Fedoseeva LA, Kumanovskaya TA Preobrazhenskiy DV (2005): Prevalence of hypertension among gas industry employees in Far North. Kardiologiya 45, 84 (in Russian)

Turchinskiy VI (1979): Cardiac aspects of human adaptation in the Far North. Vestnik AMN USS. 6, 23-32 (in Russian)

Turchinskiy VI, Sakharova SI (1979): The clinical course of myocardial infarction in young people under the conditions of the industrial city of the Far North. Kardiologiya 19, 39-45 (in Russian)

van Bergen P, Fregly MJ, Papanek PE (1992): Effect of a reduction in sodium intake on cold-induced elevation of blood pressure in the rat. Proc. Soc. Exp. Biol. Med. 200, 472-479 https://doi.org/10.3181/00379727-200-43456

Van Bergen P, Fregly MJ, Papanek PE (1992): Effect of a reduction in sodium intake on cold-induced elevation of blood pressure in the rat. Proc. Soc. Exp. Biol. Med. 200, 472-479 https://doi.org/10.3181/00379727-200-43456

Vezyraki P, Kalfakakou V, Evangelou A (2000): Atrial natriuretic peptide and thyroid hormones relation to plasma and heart calcium and magnesium concentrations of Wistar rats exposed to cold and hot ambients. Biol. Trace Elem. Res. 73, $163-173$ https://doi.org/10.1385/BTER:73:2:163

Yigiter M, Albayrak Y, Polat B, Suleyman B, Salman AB, Suleyman $H$ (2010): Influence of adrenal hormones in the occurrence and prevention of stress ulcers. J. Pediatr. Surg. 45, 2154-2159 https://doi.org/10.1016/j.jpedsurg.2010.07.027

Received: April 5, 2018

Final version accepted: January 7, 2019 